\title{
PARCERIAS EM PROJETOS DE INFRA-ESTRUTURA
}

\author{
Maria APARecida De Almeida Pinto S. Fagundes
}

I - Parceria e Direito Contemporâneo; II - Parcerias mistas e sua utilização em projetos de infra- estrutura: o "case" do setor elétrico; III - A nova perspectiva das parcerias mistas; IV - Conclusão

\section{I- Parceria e Direito Contemporâneo}

1. Na última década, tem sido intenso o debate sobre a papel do Estado, seu tamanho e competência. No contexto dessa discussão, apresenta-se a alternativa de tornar mais flexível a Administração Pública, surgindo, como tema recorrente, e ganhando especial destaque, a idéia de parcerias com o setor privado.

2. Parceria, como conota, Aurélio Buarque de Hollanda, no Novo Dicionário da Língua Portuguesa, consiste na reunião de pessoas para um fím de interesse comum.

3. Na atualidade, parceria tornou-se um daqueles vocábulos em voga, particularmente caro à retórica de autoridades governamentais. Identifica-se no ânimo de cooperação que, por intermédio dela se concretiza, notável ferramenta, a propiciar um sem número de iniciativas. Em certas hipóteses, dela tem-se lançado mão como poderoso instrumento de desenvolvimento. É que, nas circunstâncias do cenário mundial hodierno, são de tal ordem os desafios tecnológicos e a magnitude dos investimentos necessários a certas empreitadas que torna-se imperativa a agregação de esforços e recursos para viabilizá-los.

4. Para fazer frente a essa realidade, sob a designação genérica de parceria, conformam-se múltiplas combinações de esforços. Como lembram Arnoldo Wald, Luiza Rangei de Moraes e Alexandre de M. Wald (in "Direito de Parceria", p. 27), são modalidades de parcerias as associações regionais entre países, como o Mercosul, a União Européia e a NAFTA, entre universidade e indústria, entre empresas con- 
correntes, quando unem esforços na produção, na pesquisa, etc., entre moradores de um bairro para garantir a própria segurança, dentre tantos outros exemplos.

5. No mundo jurídico, como é cediço, os termos possuem uma acepção técnica própria. Uma vez enquadrada determinada relação da vida real na moldura de um tipo jurídico, produzir-se-ão os efeitos decorrentes dessa rotulação. Estarão ipso facto definidas as regras que se aplicarão à hipótese. Requer-se, pois, rigor na análise das circunstâncias que cercam o fato e no seu ajuste a determinado preceito.

6. Bem alerta Celso Antônio Bandeira de Meio (in "Curso de Direito Administrativo", pp. 478/9) que não têm serventia para o juiz, o advogado ou o intérprete "qualquer conceito, categoria ou noção, por aliciante que seja, se não lhes fornecer a indicação dos princípios e regras pertinentes à solução de questões jurídicas".

7. Essas ponderações vêm a calhar para o enfoque jurídico das parcerias, eis que o ordenamento jurídico pátrio delas pouco se ocupou. De fato, em sede de parceria, o direito brasileiro contemplava, até bem recentemente, apenas a figura da parceria rural, como modalidade de contrato bilateral e oneroso, abrangendo a parceria agrícola e pecuária, disciplinada nos arts. 1.410 a 1.423 do Código Civil de 1916, que não encontram correspondentes no Novo Código Civil, e a parceria marítima, referida no artigo 485 do Código Comercial.

8. No campo do Direito, subsumem-se, modernamente, sob o termo genérico "parceria", arranjos inominados, submetidos ao regime do Direito Público ou Privado, além daquele hoje mais notório, que é a parceria entre Estado e iniciativa privada.

9. Trata-se, contudo, de uma idéia, que, conquanto hoje muito prestigiada, não se pode considerar, propriamente, como uma novidade. Como ressalta Mauro Rodrigues Penteado, em primoroso trabalho sobre o tema, intitulado "Privatização $e$ Parcerias: Considerações de Ordem Constitucional, Legal e de Política Econômica" (in "Revista de Direito Mercantil", $\mathrm{n}^{\circ} 119$ ), há muito que se estabelecem parcerias de Direito Público Internacional e Interno, parcerias de Direito Privado e parcerias mistas, estas decorrentes de composições entre os setores estatal e privado.

10.A parceria de Direito Público Internacional se dá, por exemplo, na atuação conjunta de dois ou mais países na construção e exploração de um empreendimento comum, como é o caso da Usina de ltaipu, pertencente ao Brasil e ao Paraguai.

11. No âmbito do Direito Público Interno, celebram-se os consórcios administrativos, largamente utilizados nos Estados Unidos ("power districts") e na Itália, cuja modalidade mais comum vem a ser a dos consórcios municipais.

12. Já as parcerias na esfera do Direito Privado se inserem em um rico e variado leque de alternativas, podendo envolver desde a partilha de lucros até objetivos na área social.

13. A partir de todo o movimento mundial que se seguiu ao declínio do "welfare state", no sentido de se repensarem as dimensões do Estado, e, aqui no Brasil, particularmente, sob os influxos da Reforma do Estado e da Administração, passou a adquirir particular relevo a parceria mista, ou seja, aquela que envolve entidades públicas e privadas, significando, em algumas hipóteses, desestatização parcial ou gradual. Um dos objetivos desse tipo de parceria vem sendo a colaboração entre setor público e privado para a consecução de empreendimentos de infra-estrutura, 
de forma a sanar o déficit que se instalou nessa área, dado, sobretudo, o esgotamento da capacidade de investimento do Estado.

14. A parceria vincula-se, no mais das vezes, à concepção de uma proposta econômica. Tem-se, pois, que o coração do conceito de parceria está na conjugação de atividades, com reparação de ganhos. Essa constatação, porém, não supre a indefinição terminológica, do ponto de vista técnico-jurídico.

15. Põe-se, assim, para o operador do Direito a árdua tarefa de, diante de cada hipótese de parceria que se delineia, no sentido amplo e, como sublinhado, tecnicamente impreciso do termo, buscar sua aproximação com o instituto jurídico mais adequado, de sorte a submetê-la às regras próprias.

16. Parceria, como hoje considerada, evoca, em um primeiro momento, a idéia de sociedade. Nas palavras de Marçal Justen Filho, "a parceria é uma manifestação de sociedade, na acepção técnica da expressão". (in "Concessões de Serviços Públicos", pág 100). Há nela o matiz da "affectio societatis", no que se combinam recursos e/ou esforços para uma finalidade comum, com partilha de resultados.

17. Ocorre que as sociedades, como se sabe, estão capituladas na legislação comercial e civil, obedecendo a uma tipologia pré-definida nesse conjunto de normas.

18. Justamente em face dessa catalogação dos tipos societários na legislação e da proximidade entre o conceito de parceria e de sociedade, a que alude Marçal Justen Filho, há que se adotar precaução no trato de cada caso concreto. É que, se não se tem o cuidado de submeter a parceria em formação, claramente, aos contornos de um determinado instituto jurídico positivado, seja a uma das modalidades de sociedade, previstas na legislação, seja a outro, como, por exemplo, o consórcio, emprestando-lhe mera vestimenta de contrato entre as partes, corre-se o risco de ser aquela considerada como sociedade irregular, nos moldes do previsto no art. $305 \mathrm{e}$ seguintes do Código Comercial, agora, na dicção do art. 986 do Código Civil, sociedade em comum, ficando todos os sócios responsáveis, solidária e ilimitadamente, pelas obrigações sociais.

19. De outra parte, se a parceria envolver ente da Administração Pública, vale trazer à lembrança o ensinamento de Maria Sylvia Zanella Di Pietro (in "Parcerias na Administração Pública" p. 128), no sentido de que "o direito administrativo brasileiro não é de elaboração pretoriana; a Administração Pública, se quiser criar figuras contratuais novas, tem que procurar seu fundamento no direito positivo".

20. Se é fato que a estrutura societária oferece maior segurança, na prática ela mostra-se, por vezes, pesada, pouco flexível para negócios associativos que não se pretendem permanentes. Não por outro motivo, torna-se a cada dia mais comum o recurso à utilização da sociedade de propósito específico, constituída para a execução de objetivos determinados e específicos, como indica o nome.

21. Para além desse aspecto, não raro motivos de ordem estratégica ou até ligados a questões tributárias podem desaconselhar a agregação de investimentos sob liames societários.

22. Além disso, no caso das empresas estatais, esbarram estas no óbice que se lhes opõe a exigência constante do art.37, inciso XX, da Constituição Federal, no sentido de estarem obrigadas a contar com autorização legislativa para participação em empresas privada. Muito embora o alcance desse preceito constitucional seja 
objeto de controvérsia doutrinária, entendendo alguns que a restrição não se aplicaria às subsidiárias das sociedades de economia mista, o fato é que, no momento da modelagem da parceria, é natural que se dê preferência à solução mais conservadora, que não suscite dúvidas, nem questionamentos por parte dos órgãos de controle.

23. Em virtude das razões acima mencionadas, as partes interessadas em convergir esforços em determinado empreendimento optam, em certas circunstâncias, por um acerto empresarial que não envolva a constituição de outra pessoa. Ou seja, busca-se uma forma associativa não personalizada, resguardando-se a autonomia jurídica das partes, que realizam as atividades em nome próprio.

24. Nessa linha, uma alternativa que se apresenta é a adoção da sociedade em conta de participação, antes arrolada no Código Comercial (art. 326 e seguintes), atualmente disciplinada no art. 991 e seguintes do Código Civil, que a inclui entre as sociedades não personificadas, ao lado da sociedade em comum. Se bem que se trate, sem dúvida, de uma sociedade, reveste ela características especialíssimas, que lhe emprestam feição bem peculiar, em relação às demais.

25. Não possuindo personalidade jurídica distinta da de seus sócios, rege-se por um contrato entre o sócio ostensivo ou aparente e os sócios ocultos, respondendo perante terceiros apenas aquele, o que dota a associação de maior maleabilidade. A respectiva constituição independe de quaisquer formalidades, não demandando registro na Junta Comercial. Aliás, cuida o novo Código Civil de prever que mesmo a inscrição do contrato social em qualquer registro não terá o condão de conferir personalidade jurídica à sociedade.

26. Deve-se admitir que, para implementação de parcerias mistas, o recurso à sociedade em conta de participação poderia conflitar com princípios da Administração Pública, como o da publicidade.

27. Há, contudo, em relação a essa sociedade uma desconfiança, de ordem geral, inspirada, provavelmente, como lembra João Luiz Coelho da Rocha, em estudo intitulado "Novas Alternativas e Derivações Jurídicas para a Agregação Empresarial" (in "Revista de Direito Mercantil", vol.1 18, p. 95) pela "depreciação "cultural" de uma posição jurídica conceituada como "oculta", aquela do sócio que não desponta." Nota-se, inclusive, que, talvez em virtude disso, é escassa a doutrina sobre a sociedade em conta de participação, destacando-se os ensaios já clássicos de Mauro Brandão Lopes.

28. Não se pode, todavia, deixar de observar que o novo Código Civil dela se ocupou, remetendo, inclusive, à disciplina subsidiária da sociedade simples, o que pode significar que tal instituto venha a despertar mais interesse daqui para frente.

29. Bem pelos motivos antes referidos, encontram-se, com maior freqüência, agregações empresariais organizadas sob a moldura do consórcio, figura jurídica contemplada nos arts. 279 e 280 da Lei $n^{\circ}$ 6404/76, uma manifestação do conceito anglo-saxão amplo de "joint venture".

30.0 consórcio, posto que de larga utilização, carece, ainda hoje, de balizamentos que melhor o regulem. Um de seus traços marcantes consiste em não possuir personalidade jurídica, obrigando-se as partes nos termos do contrato que celebrarem. Ou seja, apesar de, como se verifica da etimologia da palavra (com sorte), sob a 
roupagem desse instituto, dar-se destino comum à sorte de duas ou mais empresas, cada uma delas preserva a respectiva individualidade.

31. De outra parte, não há presunção de solidariedade entre os partícipes, que, para existir, deverá ficar prevista no contrato, exceto para os efeitos do Código de Defesa do Consumidor, cujo art. $28, \S 3^{\circ}$ prevê que as sociedades consorciadas serão solidariamente responsáveis pelas obrigações decorrentes do mesmo. Observe-se que a aplicação da norma inscrita no "caput" do dispositivo, que acolhe a disregard doctrine, pode implicar, inclusive, na responsabilização dos sócios ou acionistas das empresas consorciadas.

32. O consórcio, à luz da lei societária, tem natureza efêmera, eis que se trata de união voltada para a execução de um empreendimento determinado.

33. Registre-se, por oportuno, que, em outros países, já se evoluiu, em relação ao assunto, reconhecendo-se associações permanentes de empresas, sem qualquer espécie de participação acionária umas nas outras. Em outras palavras, trata-se de agregações que transcendem um objetivo limitado de realizar determinado empreendimento, tornando-se, ao contrário, perenes. São os chamados agrupamentos, analisados por Jorge Lobo no instigante estudo "Direito dos Grupos de Sociedades". (in "Revista de Direito Mercantil", pág. 99 e seguintes)

34. Aqui entre nós, na montagem de contratos de consórcio devem ser observados cuidados, como a rigorosa definição do respectivo escopo, a determinação do prazo e o registro na Junta Comercial, nesse caso, exigível, em contraste com a disciplina da sociedade em conta de participação, sob pena de submeter-se a agregação aos riscos das sociedades em comum.

\section{II - Parcerias mistas e sua utilização em projetos de infra- estrutura: o "case" do setor elétrico}

35. Na implementação das parcerias mistas esbarrou-se, desde o início, na inexistência de um aparato legal adequado. A Administração Direta e Indireta, em suas atividades, estão sujeitas à observância dos preceitos constitucionais e das normas do Direito Administrativo, cujas pedras angulares são, como preleciona Celso Antonio Bandeira de Mello "Curso de Direito Administrativo", p. 26), a supremacia do interesse público e a sua indisponibilidade pela Administração.

36. O que se verifica é que o termo parceria, nessa seara, vem sendo utilizado como gênero, no sentido amplo de cooperação entre a Administração e os particulares, englobando sociedades, consórcios, a concessão e permissão de prestação de serviço público, franquias, terceirizações, convênios, acordos de programa.

37. Contudo, se o conceito de parceria, como antes frisado, envolve partilha de resultados, nem todos esses institutos se amoldariam à idéia que ela expressa, quando se desce a um nível mais detalhado de exame.

38. Nessa linha, não se pode considerar, por exemplo, a concessão uma genuína manifestação de parceria. Por mais que se queira elastecer o relacionamento entre poder concedente e concessionário, como preconizam alguns estudiosos da matéria, com base em experiências colhidas em outros países, por mais que se imprima um 
caráter menos autoritário, mais flexível, ao Direito Administrativo, o certo é que, na concessão, por exemplo, não há partilha de resultados. Além disso, o poder concedente, como corolário de um dos pilares daquele Direito - a supremacia do interesse público - estará sempre em situação privilegiada e de preponderância na relação com os particulares, gozando de prerrogativas, contempladas nas cláusulas chamadas "exorbitantes", o que não se compatibiliza com a noção de parceria.

39. A nova configuração das relações entre a sociedade e o Estado tem suscitado reflexões por parte dos estudiosos do Direito, instigadas pela necessidade de se reverem conceitos e procedimentos, de sorte a permitir que a Administração Pública dê conta dos cometimentos que lhe são confiados, a partir da perspectiva da atual realidade.

40. Alguns autores, como Arnoldo Wald (ob. cit.), sugerem que, se é fato que as contingências têm levado à reinvenção do Estado e ao seu redimensionamento, cabe refletir sobre a conformação do Direito Administrativo com essa nova realidade factual. Preconiza que, tendo em vista os profundos desafios e rápidas mudanças do mundo moderno, as regras rígidas desse Direito se flexibilizem, revejam-se regimes jurídicos, construa-se uma nova dogmática jurídica, de tal sorte que fórmulas de cooperação, como parcerias, ganhem espaço, concretizem-se.

41. Em trabalho recentemente publicado na "Revista de Direito Administrativo" (vol. 231, pp. 129 a 156), Diogo de Figueiredo Moreira Neto analisa novos institutos consensuais da ação administrativa, sublinhando que

"a administração dos interesses públicos a cargo do Estado pode ser realizada diretamente - pelos órgãos executivos da União, dos Estados, do Distrito Federal (e dos Municípios; - indiretamente - pelos entes públicos por eles criados, como autarquias, paraestatais (integrantes da administração indireta); e associadamente - através de pessoas jurídicas de direito privado que se aliam ao Estado sob um vínculo de colaboração de direito público".

42. Ensina o conceituado administrativista que, a depender da natureza da entidade privada associada, aquilo que a doutrina denominou administração privada associada de interesses público pode realizar-se sob múltiplas formas, contratuais ou não.

43. Dentre as parcerias instituídas por vínculo contratual, cita as concessões de serviços públicos e de uso de bem público, permissão de serviços públicos, arrendamento portuário, arrendamento operacional, franquia pública, gerenciamento privado de entidade pública, venda de bilheteria e contrato de risco. Menciona, outrossim, a execução associada não contratual, cujo traço marcante é a coordenação das atividades dos parceiros públicos e privados, a fazer-se mediante convênios, acordos de programa ou "joint ventures" públicas.

44. Maria Sylvia Zanella di Pietro (ob. cit., pp.128/9), após abordar, minuciosamente, o tema das parcerias na Administração Pública, alerta para a dificuldade de se adotarem figuras contratuais novas, não contempladas no direito positivo, assinalando que 
"o entusiasmo pela privatização (entendida no sentido de busca pelo regime jurídico de direito privado para a Administração Pública), não pode chegar ao ponto de tornar letra morta o princípio da legalidade, porque sem este não se pode falar em Estado de Direito.

O que se verifica é uma acentuada oposição entre os tecnocratas e os burocratas, entre o princípio da eficiência, pregado pela (Ciência da Administração, e o principio da legalidade imposto pela Constituição e inerente ao Estado de Direito."

45. Já Marçal Justen Filho (ob. cit., pp. 991103) vê com muita reserva a utilização da parceria pela Administração Pública. Vislumbra uma incompatibilidade entre o caráter informal desse tipo de associação e o regime de direito público, especialmente na hipótese de prestação de serviço público, em que o nivelamento com o parceiro seria impossível e aponta os riscos de responsabilidade trabalhista solidária. Além disso, com base no art. 37, inciso XX, da Constituição Federal, entende necessária autorização legislativa para que tal parceria se forme, partindo do pressuposto de que, se ela se impõe, na hipótese de criação de uma sociedade de economia mista, não pode ser prescindida em se tratando de uma associação com o capital privado. A essa opinião, contrapõe-se o argumento de que, no caso, não há a constituição de nova pessoa jurídica, não procedendo a invocação do citado dispositivo constitucional.

46. As questões acima suscitadas acerca das parcerias mistas são exemplarmente ilustradas pelas experiências relativas a projetos de infraestrutura, especialmente no setor de energia elétrica.

47. Malgrado a deficiência do arcabouço legal para melhor enquadramento das parcerias, em geral, e, particularmente, para que se encetassem as parcerias mistas, iniciativas dessa natureza ocorreram no setor elétrico, nos últimos anos, em diferentes momentos, e para finalidades diversas, mas quase sempre em função da necessidade do aporte de capitais privados para conclusão de obras ou expansão do sistema.

48. A partir de meados da década de 80 , o setor elétrico brasileiro passou a enfrentar graves problemas de ordem econômica, financeira e institucional, resultando na paralisação de obras indispensáveis para o País. As projeções feitas pelo planejamento estratégico indicaram a necessidade de retomada urgente dessas obras, na década seguinte, para minimizar as conseqüências de um desabastecimento que se anunciava - e que, de fato, ocorreu.

49. Além dessa premência de atender a futura demanda, lembre-se que tais obras paralisadas, sobre não propiciarem retorno de rentabilidade pelo investimento já feito, estavam sujeitas a deteriorarem-se. Em alguns casos, os juros referentes aos empréstimos tomados para viabilizá-las continuavam a correr e a serem pagos, sem perspectivas de geração de receita, com incremento, portanto, dos custos de construção.

50. Em face das constrições constitucionais para que empresas estatais se associem a empresas privadas sob estrutura societária, o modelo mais utilizado, inicial- 
mente, para a combinação de esforços entre as empresas da Administração, detentoras das concessões dos aproveitamentos hidrelétricos, cujas obras estavam paradas, e a iniciativa privada foi o consórcio.

51. Em geral, o desenho desses arranjos consorciais envolvia o aporte de recursos pela iniciativa privada para retomada e conclusão das obras, mediante compromisso de receber energia em contrapartida, cabendo à entidade estatal o gerenciamento das obras e das questões ambientais e a operação futura da usina.

52. Embora o vetusto Código de Águas já referisse a possibilidade da formação de consórcios para a geração de energia (art. 201), e a lei societária contenha a disciplina desse instituto, muito se exigiu, em termos de construção legislativa e jurídica, para viabilizar dita associação entre as concessionárias estatais e a iniciativa privada, com o objetivo de permitir tal conclusão. É que, àquela altura, não se dispunha de moldura regulatória que respaldasse providências, como a transferência e prorrogação de concessões, cruciais para a montagem de parcerias.

53. Como sói acontecer, os fatos se anteciparam ao direito, impondo o surgimento de uma formulação jurídica que respaldasse as iniciativas que proviam soluções para a realidade do País.

54. Nessa esteira, em 1993, foi editado o Decreto ${ }^{\circ} 915$, autorizando a constituição de consórcio para geração de energia, inclusive entre concessionário e autoprodutores, ao qual seria transferida a concessão. Esse Decreto viabilizaria a construção da Usina de Igarapava, cuja concessão fora outorgada à CEMIG. O Consórcio agregava esforços desta última e de várias outras empresas (Companhia Vale do Rio Doce, Usiminas e Mineração Morro Velho), que inverteriam recursos no projeto para fazerem jus à percepção de parte da energia que viria a ser gerada.

55. Também com apoio nesse Decreto, a Centrais Elétricas do Sul do Brasil Eletrosul licitou parceiros para construir e explorar a Usina de Itá, de cuja concessão era titular.

56. Uma das questões jurídicas bastante debatidas à época centrava-se na necessidade da entidade da Administração Pública promover tal certame para a escolha de parceiro com o objetivo de a ele consorciar-se, dividindo-se as opiniões dos estudiosos a respeito do tema.

57. Uma corrente, conquanto reconhecendo que as disposições da Lei $n^{\circ} 8.666$, de 21 de junho de 1993, não se endereçam a tal hipótese, mas à contratação pertinente a obras, serviços, compras, alienações, concessões, permissões e locações da Administração Pública, remete-se aos princípios insculpidos no "caput" do art. 37 da Constituição Federal para entender exigível a licitação.

58. Há, de outro lado, opiniões respeitáveis que vislumbram, na espécie, uma não incidência do princípio da licitação, eis que não se cuida, no caso, como assinalado, das situações a que se dirigem o art. 37, inciso XXI, da Constituição Federal e o art. 20, parágrafo único, da Lei ${ }^{\circ} 8.666 / 93$.

59. Para além das conjecturas quanto à forma de seleção do parceiro, chegou-se, também a aventar a possibilidade de a presença do ente estatal "contaminar" o consórcio, impondo-lhe todas as restrições aplicáveis àquele, como, por exemplo, a obrigatoriedade de fazer preceder de licitação a aquisição de bens e serviços para o projeto. A solução mais sensata indicava que tais constrições só incidiriam na atuação 
isolada do membro do consórcio que integrasse a Administração Pública, até porque os consórcios não estariam incluídos dentre os destinatários dos comandos da Lei $\mathrm{n}^{\circ} 8.666 / 93$.

60. A Advocacia Geral da União, ao examinar a experiência pioneira do consórcio formado para construir a Usina de Itá, em decorrência de licitação promovida pela Eletrosul, com apoio no Decreto $\mathrm{n}^{\circ} 915$, julgou questionáveis pontos, como a circunstância de mero decreto autorizar a transferência de concessão e a modificação da destinação da energia a ser produzida. E mais: suscitou dúvidas quanto à possibilidade, à luz do quadro legal então existente, de prorrogação das concessões, o que, frise-se, mostrava-se indispensável para permitir a amortização do investimento privado.

61. Entendendo que o Decreto $n^{\circ} 915$ não oferecia respaldo à superação desses impasses, o Advogado-Geral da União emitiu o Parecer $n^{\circ}$ GQ-58, opinando pela anulação da licitação.

62. Também o Tribunal de Contas da União, no acompanhamento do referido processo licitatório, vislumbrou indícios de irregularidades, percepção que decorreu, em grande parte, do caráter inédito da iniciativa daquela empresa. Nessa trilha, chegou a determinar que fosse sustada a celebração do contrato com o parceiro selecionado.

63. Logo em seguida, porém, sobrevieram a Lei $n^{\circ} 8.987$, que regulamenta o art.175 da Constituição Federal, e a Lei $\mathrm{n}^{\circ}$ 9.074, que a complementa, ambas promulgadas em 1995. As dúvidas acima aludidas foram aclaradas por esses diplomas legais. O primeiro deles disciplinou a transferência de concessão. $O$ segundo traçou regras para formação de consórcios para geração de energia, autorizando a modificação de finalidade da energia e a prorrogação de concessões, tendo convalidado, no respectivo art. 21 , situações anteriores, como a de Itá.

64. Em virtude da edição dessas leis, a AGU e o TCU alteraram suas posições sobre o caso de ltá, ressaltando-se que o Ministério Público junto àquela Corte externou opinião no sentido de que, em face de dispositivos nelas contidos, "parece evidente o intuito do legislador de afastar o princípio da obrigatoriedade de licitação na constituição dessa modalidade de associação comercial entre capitais públicos e privados". (Decisão n 358/95, do Plenário do TCU, publicado no "Diário Oficial da União", de 14.08.95)

65. Além do consórcio, outras modalidades de parceria foram adotadas em projetos do setor elétrico, como o arrendamento, contemplado no Decreto $\mathrm{n}^{\circ} 1.348$, de 28 de dezembro de 1994, utilizado para conclusão da Usina de Serra da Mesa, de que é concessionária Furnas Centrais Elétricas.

66. Essa alternativa foi concebida antes do advento da legislação que disciplinou as concessões, corno uma forma de contornar as dificuldades mencionadas anteriormente, e teve por esteio a prática de arrendamento de equipamentos entre concessionários, previsto no Plano de Contas do Serviço Público de Energia Elétrica.

67. Aqui também se pôs a dúvida quanto à necessidade do arrendamento submeter-se ao procedimento licitatório, previsto na Lei $n^{\circ} 8.666 / 93$. Opinando sobre o assunto, em parecer solicitado por Furnas, Caio Tácito manifestou entendimento, com a lucidez de sempre, no sentido de que 
"a adoção do modelo de parceria, a importar no arrendamento, não se enquadra nas hipóteses taxativamente arroladas na lei em causa".

68. O desenho consistiu, pois, na seleção de parceiro, de forma simplificada, com convite a todos os concessionários de energia, regularizados junto ao então Departamento Nacional de Energia Elétrica - DNAEE, para concluir a obra, arrendando aquele a Furnas as instalações de sua propriedade, mediante o recebimento de parte da energia produzida.

69. No processo de seleção saiu vitoriosa a Energisa, uma concessionária privada, permanecendo, porém, Furnas como a única concessionária do aproveitamento. Ao contrário do arranjo eleito para Itá, não houve, neste caso, transferência de concessão, nem modificação da destinação da energia, direcionada para o serviço público. Ademais, em lugar da prorrogação da concessão, optou-se por estabelecer prazo de arrendamento que garantisse a amortização do investimento.

70. É importante notar que, já sob o regime da Lei $\mathrm{n}^{\circ} 8.987$ e, sobretudo, da Lei $n^{\circ} 9.074$, a associação com a iniciativa privada para a conclusão de obras de unidades geradoras de energia tornou-se obrigatória, sob pena de extinção das concessões outorgadas a estatais. Lembre-se, por oportuno, que, como antes mencionado, a Lei $\mathrm{n}^{\circ} 9.074$ autorizou, expressamente, a constituição de consórcios com o objetivo de geração de energia.

71. Cabe registrar, ainda, as inúmeras experiências de parcerias, voltadas para implantação de usinas termelétricas, no bojo das quais a associação entre capitais públicos e privados tem-se dado sob variada formatação.

72. Os acordos envolvem uma complexa engenharia contratual, em que a empresa estatal entra com a competência que detém na obtenção de autorizações, na instalação e operação da unidade e se compromete, muitas das vezes, a comprar a energia a ser produzida. Os outros partícipes desses acordos podem ter atribuições variadas, dependendo do negócio. Tais arranjos demandam a celebração de vários contratos, tais como os de consórcio, constituição de sociedade de propósito específico, financiamento, "power purchase agreement", fornecimento de gás, Operação da unidade etc.

73. Cumpre citar, nesse rol de iniciativas, aquelas de que tem participado a Petrobrás, integrando o "equity" do empreendimento e fornecendo o gás, sob modalidade diferenciada de ajustes.

74. Merece destaque, ainda, a autorização contida, originariamente, no art. 15 da Lei ${ }^{\circ} 3.890$-A, de 25 de abril de 1961, com a redação da Lei ${ }^{\circ} 9.648$, de 27 de maio de 1998, para a Eletrobrás participar, corno acionista minoritária, de concessionárias privadas de geração e de transmissão de energia elétrica. Aqui a parceria assume a feição de sociedade, tendo sido utilizada para viabilizar inúmeros projetos, destacadamente na área de transmissão de energia.

75. Mais recentemente, a Lei $n^{\circ} 10.438$, de 26 de abril de 2002, trouxe nova alteração ao citado art. 15 da Lei $n^{\circ} 3.890-\mathrm{A} / 61$, desta feita para permitir que não apenas a Eletrobrás, mas, ainda, suas controladas, possam associar-se, sem poder de controle, a consórcios ou sociedades, que se destinem à produção ou transmissão de 
energia elétrica, sob o regime de autorização ou concessão, ampliando, portanto, o alcance da anterior provisão legal.

\section{III - A nova perspectiva das parcerias mistas}

76. Dando sequência às variadas experiências no campo das parcerias mistas, o Governo pretende agora implementar os Programas de Parcerias Públicas, também denominadas Parcerias Público-Privadas (PPP's).

77. Trata-se de modalidade de cooperação entre Estado e iniciativa privada, já adotada por vários países, a exemplo da Inglaterra pós-Margareth Tatcher, como mecanismo destinado a facilitar a implantação de uma gama de projetos, nas áreas de transporte, água, saneamento, energia, educação, saúde, segurança pública.

78. Os contratos de PPP podem revestir formas diversificadas, combinando projeto, financiamento, construção, operação, manutenção, posse, transferência, arrendamento. Como toca ao parceiro privado alavancar o capital, tem ele intensa participação em todas as fases do projeto.

79. A instituição das Parcerias Público-Privadas depende, no momento, de modificações a serem introduzidas na legislação que disciplina as concessões de serviços públicos, de sorte a que esta contemple os conceitos que constituem seus pilares, a saber, a transferência da maior parte dos riscos ao setor privado, o ajuste dos custos aos riscos ao longo de toda a duração da concessão e o desenvolvimento de um mecanismo de pagamentos, orientado pela idéia de remunerar apenas os serviços efetivamente prestados, reduzindo desembolsos em caso de perda da qualidade do serviço e distribuindo prêmios pelo aprimoramento da qualidade.

80. De outra parte, a viabilidade desse modelo de parceria ficará sujeita a definição, no arcabouço legal de condições adequadas de garantia aos investimentos que serão assumidos pela iniciativa privada, vislumbrando-se, como possibilidades, a criação de fundos garantidores, bem como de linhas de financiamento compativeis com os custos e prazos dos empreendimentos.

\section{IV - Conclusão}

81. As reflexões feitas sobre a evolução do conceito de parceria no Direito Contemporâneo deixam evidente que as contingências do mundo moderno tornam imprescindível o recurso a múltiplos arranjos de cooperação entre as entidades, notadamente no campo das associações mistas, voltadas para a viabilização de obras de infra-estrutura, vitais para o desenvolvimento do País, trazendo a reboque a superação dos obstáculos de ordem jurídica que se antepunham à sua concretização, com a construção e aprimoramento da moldura regulatória necessária. 